Article

\title{
Performance Characteristics of PTC Elements for an Electric Vehicle Heating System
}

\author{
Yoon Hyuk Shin ${ }^{1}$, Seung Ku Ahn ${ }^{2}$ and Sung Chul Kim ${ }^{3, *}$ \\ 1 Green Car Power System R\&D Division, Korea Automotive Technology Institute, 74 Yongjung-ri, \\ Pungse-myun, Dongnam-gu, Chonan-si, Chungnam 330-912, Korea; yhshin@katech.re.kr \\ 2 R\&D Center, 67-2 Sangdaewon-dong, Jungwon-gu, Seongnam-si, Kyeonggi 462-120, Korea; \\ ask29@eguntech.com \\ 3 School of Mechanical Engineering, Yeungnam University, 280 Daehak-ro, Gyeongsan-si, \\ Gyeongbuk 712-749, Korea \\ * Correspondence: sungkim@ynu.ac.kr; Tel.: +82-53-810-2572; Fax: +82-53-810-4627
}

Academic Editors: Samuel Gendebien and Vincent Lemort

Received: 6 July 2016; Accepted: 30 September 2016; Published: 11 October 2016

\begin{abstract}
A high-voltage positive temperature coefficient (PTC) heater has a simple structure and a swift response. Therefore, for cabin heating in electric vehicles (EVs), such heaters are used either on their own or with a heat pump system. In this study, the sintering process in the manufacturing of PTC elements for an EV heating system was improved to enhance surface uniformity. The electrode production process entailing thin-film sputtering deposition was applied to ensure the high heating performance of PTC elements and reduce the electrode thickness. The allowable voltage and surface heat temperature of the high-voltage PTC elements with thin-film electrodes were $800 \mathrm{~V}$ and $172{ }^{\circ} \mathrm{C}$, respectively. The electrode layer thickness was uniform at approximately $3.8 \mu \mathrm{m}$ or less, approximately $69 \%$ less electrode materials were required compared to that before process improvement. Furthermore, a heater for the EV heating system was manufactured using the developed high-voltage PTC elements to verify performance and reliability.
\end{abstract}

Keywords: performance characteristics; positive temperature coefficient (PTC) element; screen printing; sputtering; electric vehicle; high voltage

\section{Introduction}

The automobile industry is striving to replace internal combustion engine vehicles with environmentally friendly electric vehicles (EVs) to address global energy depletion and environmental pollution. The one-charge driving range of EVs must be improved to boost EV use by reducing battery power consumption, which requires the development of a highly efficient EV heating system [1,2].

Apart from powering the vehicle engine, the EV heating system accounts for the majority of energy consumption; therefore, some recent studies have applied high-efficiency heat pumps for heating to improve the driving range of EVs [3-5]. The performance of heat pump systems tends to deteriorate at low temperatures and in open air. A high-voltage positive temperature coefficient (PTC) heater has a simple structure and a swift response; hence, for cabin heating in EVs, such heaters have been used on their own or with a heat pump system [6-8].

The PTC element used in a high-voltage heater is an electric heat source that ensures safety by not exceeding the design temperature. It is universally used in vehicle heating systems. Moreover, to maximize the advantages of the PTC elements' swift response, securing the performance and reliability of the high-voltage PTC element by considering the driving environment and the characteristics of repeated operations is becoming increasingly crucial as air heaters that directly heat the air flowing into the vehicle are being actively adopted for EV heating. 
Cen and Wang [9] investigated the current PTC element manufacturing process and developed PTC elements with enhanced heating performance and durability. The raw material composition of any PTC element strongly influences PTC characteristics such as temperature and resistance. Accordingly, a uniform mixture can ensure stable element performance. Therefore, the physical mixture process and the forming equipment's compressive force, which ensures adequate and uniform density and optimizes the sintering time inside the furnace, are crucial and must be improved [10]. Moreover, the PTC heating elements must ensure surface flatness for ease of packaging.

In particular, the electrode production process, which is based on existing screen printing methods, must be improved to ensure PTC element performance and electrical durability and to reduce electrode material cost. The physical and material characteristics of the electrode part of the PTC element, which is a structure connecting different materials, strongly affect the element's performance and reliability; improving this process is the most difficult. Furthermore, screen printing consumes the electrode material, which is expensive, and producing a uniform electrode layer on the element's surface is difficult.

Therefore, this study improved the sintering process in the PTC element manufacturing to enhance surface uniformity. The electrode production process entailing thin-film sputtering deposition was applied to ensure the heating performance of the PTC elements and to reduce the amount of electrode material required. In addition, a heater for an EV heating system was manufactured using the developed high-voltage PTC elements to verify their performance.

\section{Fabrication of PTC Element}

The PTC element was manufactured by forming a structure stacked with electrode layers to transmit power to semiconductive ceramic materials (Figure 1). The technical development of the key processes for the element, namely sintering and electrode production, are detailed herein.

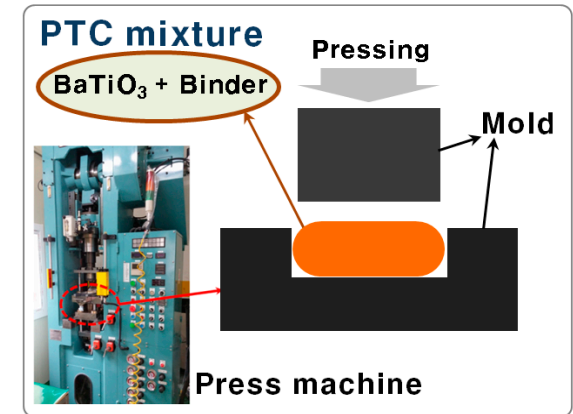

Molding process

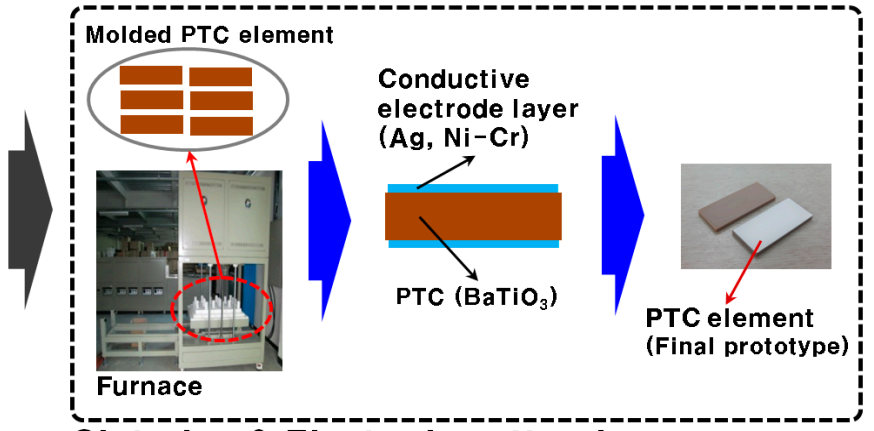

Sintering \& Electrode patterning process

Figure 1. Schematic of the positive temperature coefficient (PTC) element manufacturing process.

\subsection{Sintering}

The outer component of the PTC element for heating was manufactured from a compound containing barium titanate $\left(\mathrm{BaTiO}_{3}\right)$, additional raw materials, and binder using a press device. Subsequently, the component was sintered in a furnace of at least $1300{ }^{\circ} \mathrm{C}$ to combine the compounds and increase its rigidity. The surface flatness of the plate-type element may deteriorate because of thermal deformation. However, the PTC elements for heaters must smoothly conduct heat through contact. Therefore, the temperature distribution uniformity of each PTC element must be ensured inside the furnace to enhance the surface flatness of the PTC elements during sintering. Appropriate plates were used for layering inside the furnace (Figure 2) to minimize the distortion of the PTC element during sintering. Silicon carbide ( $\mathrm{SiC})$, which has a high thermal conductivity, was used as the material for the base plate to enhance the temperature distribution uniformity within the furnace. 
The SiC base plate also minimized bending and thickness variations by further equalizing the PTC element's sintering temperature distribution.

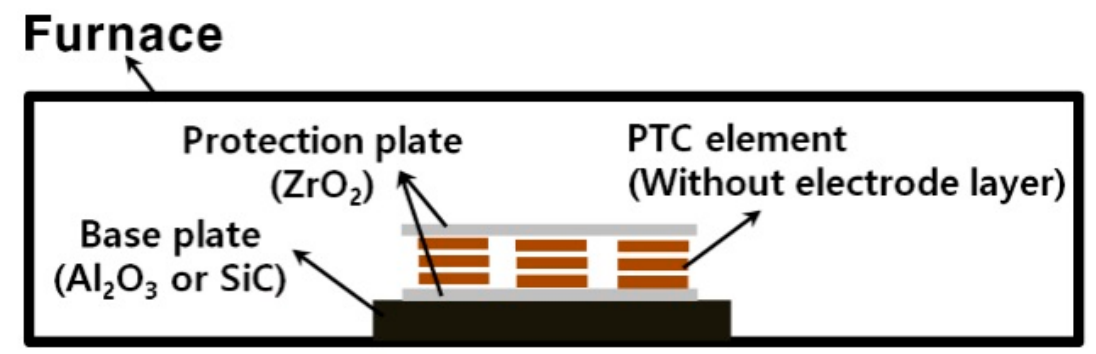

Figure 2. Schematic of the PTC element sintering process.

After sintering, the flatness and thickness variations of the PTC elements were measured (Figure 3). Table 1 lists the characteristics for each sintering process and the corresponding measurement results. When $\mathrm{SiC}$ was used as the base plate material, thickness variation reduced by approximately $60 \%$ compared with that obtained when aluminum oxide $\left(\mathrm{Al}_{2} \mathrm{O}_{3}\right)$ was used; this result is indicative of the enhanced flatness of the PTC elements.

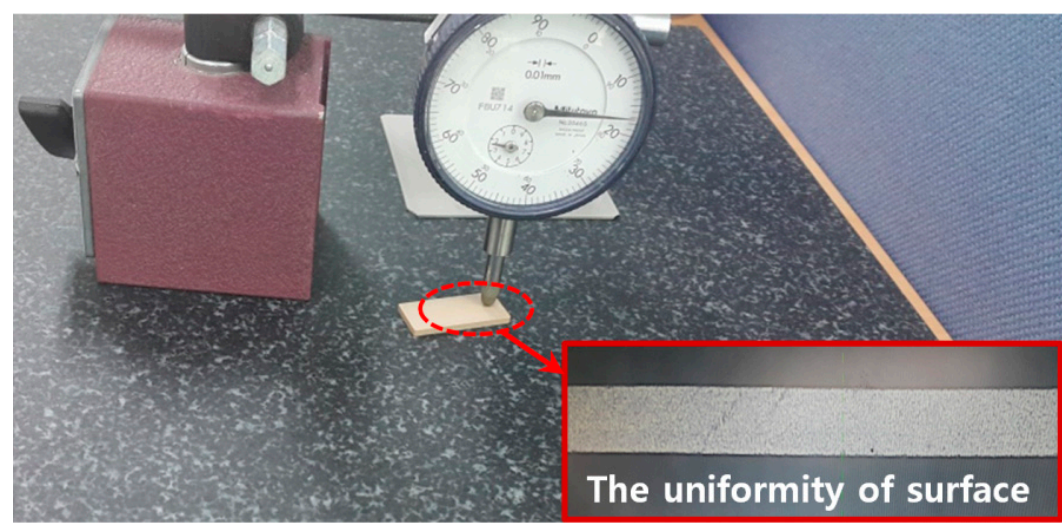

Figure 3. Measuring PTC element thickness.

Table 1. Specifications of the conventional and improved positive temperature coefficient (PTC) element sintering processes.

\begin{tabular}{ccc}
\hline \multirow{2}{*}{ Parameter } & \multicolumn{2}{c}{ Specifications of Sintering Process } \\
\cline { 2 - 3 } & Conventional Method & Improved Method \\
\hline Sintering temperature $\left({ }^{\circ} \mathrm{C}\right)$ & 1310 & 1310 \\
Base plate & $\mathrm{Al}_{2} \mathrm{O}_{3}$ & $\mathrm{SiC}$ \\
Thermal conductivity $(\mathrm{W} / \mathrm{m} \cdot \mathrm{K})$ & 25.0 & 77.5 \\
Thickness variation of the PTC element $(\mathrm{mm})$ & 0.15 & 0.05 \\
Size of the PTC element $\left(\mathrm{mm}^{3}\right)$ & $28.5 \times 12.9 \times 2.1$ (length $\times$ width $\times$ thickness) \\
\hline
\end{tabular}

\subsection{Electrode Production}

Producing electrodes on the element surface is the most critical procedure in the manufacturing of PTC elements for heaters. To enhance element performance by improving contact between materials and to reduce the cost of the base materials in the electrode layer, this study actively applied the sputtering method instead of the existing screen printing method as shown in Figure 4. Table 2 details the specifications of the sputtering equipment. The electrode layer inputs electric energy into the PTC element. The performance and durability of the electrode is dependent on the characteristics of its 
core because it is formed at the surface, where the heater's thermal energy is released. Electrode layers must be adequately thick (at least $10 \mu \mathrm{m}$ ) to withstand the voltage induced during screen printing. The characteristics of electrode layers composed of metallic materials (e.g., $\mathrm{Ag}$ and $\mathrm{Al}$ ) differ from those composed of ceramic materials (e.g., $\mathrm{BaTiO}_{3}$ ).

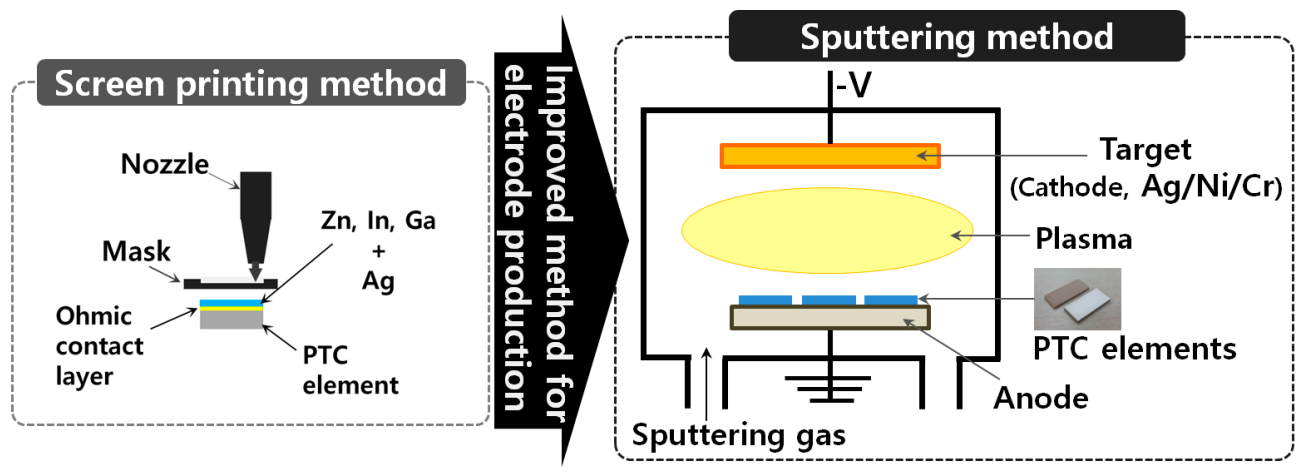

Figure 4. Schematic of the improved electrode patterning method.

Table 2. Specifications of the thin-film deposition (sputtering) equipment.

\begin{tabular}{cc}
\hline Chamber size $\left(\mathrm{m}^{3}\right)$ & $3015 \times 2450 \times 3700($ width $\times$ height $\times$ depth $)$ \\
Substrate rotation & 28 axes $(80 \mathrm{rpm})$ \\
Pump & Cryo pump $(22$ inch) 2 ea \\
Cathode power $(\mathrm{kW})$ & 20 \\
Input voltage $(\mathrm{V})$ & $\mathrm{DC} 380$ \\
Vacuum gauge $($ Torr $)$ & $1 \times 10^{-6}-760$ \\
\hline
\end{tabular}

Figure 5 presents the cross-sections of the PTC elements manufactured through the existing screen printing method and the new sputtering method. Compared with screen printing, the sputtering method reduced electrode material use by approximately $69 \%$. Moreover, contact uniformity of the electrode improved.

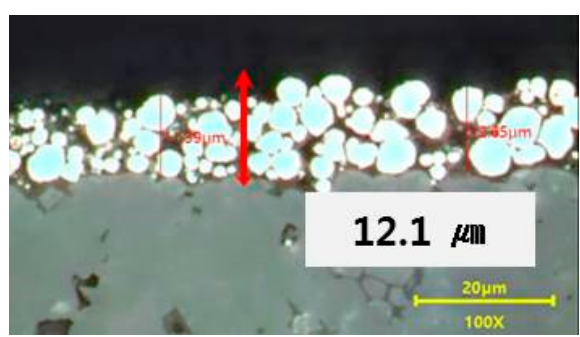

(a)

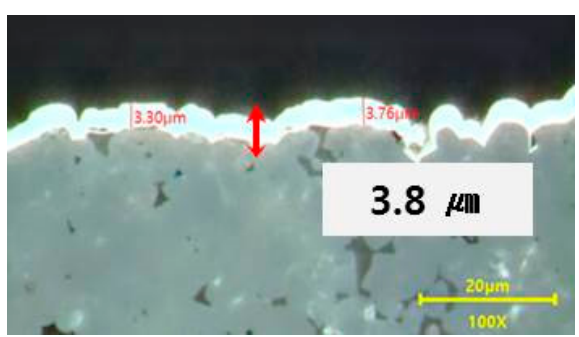

(b)

Figure 5. Electrode thickness of PTC elements fabricated through (a) screen printing and (b) sputtering.

\section{Performance Characteristics of the PTC Element}

The variations in the resistance of the high-voltage PTC element prototypes manufactured through both electrode production processes were measured as a function of temperature by using the experimental devices shown in Figure 6. The resulting characteristic curves are presented in Figure 7 and summarized in Table 3. The temperature at which resistance sharply increases is called the switching temperature or the Curie temperature $\left(T_{c}\right)$. It is the most representative parameter of any temperature-resistance characteristic curve and is generally defined as the temperature at which the resistance is two times the minimum resistance or the resistance at the reference temperature $\left(25^{\circ} \mathrm{C}\right)$. The operating $T_{c}$ range during sputtering $\left(\sim 175^{\circ} \mathrm{C}\right)$ is almost equal to that during screen 
printing, which indicates that proposed approach can realize the operation range required for EV heating. Moreover, the temperature-resistance characteristics of the prototype fabricated through sputtering (prototypes $\mathrm{C}$ and $\mathrm{D}$ in Table 3 ) are similar to those fabricated through screen printing (prototypes A and B).
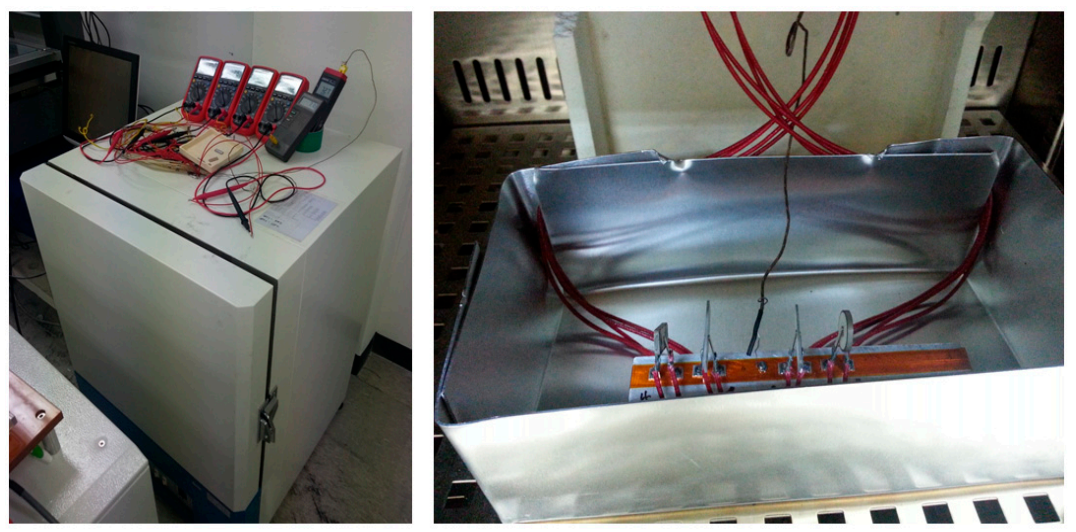

Figure 6. Measuring the temperature-resistance characteristics of the PTC elements.

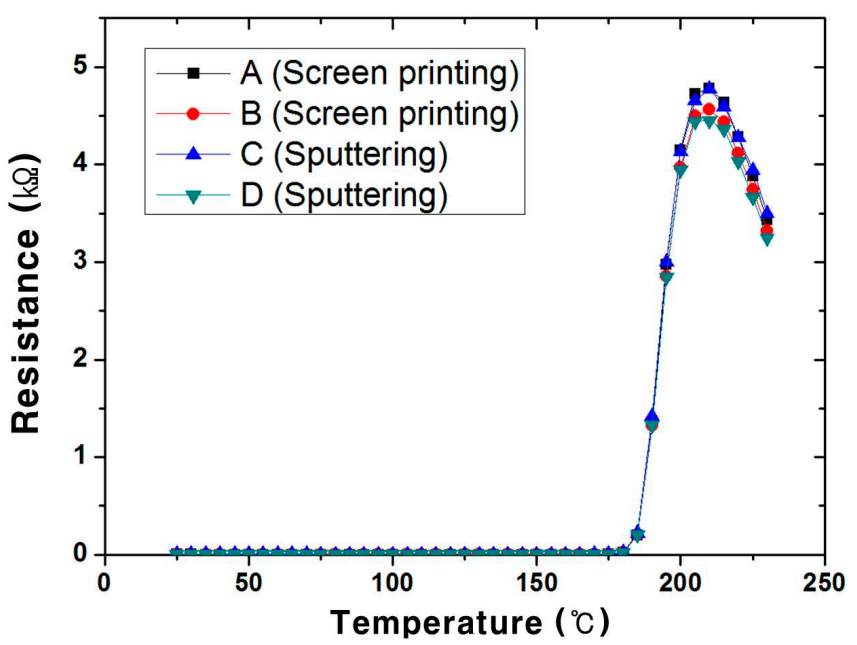

Figure 7. Temperature-resistance characteristics of high-voltage PTC element prototypes manufactured through screen printing and sputtering.

Table 3. Temperature-resistance characteristics of the PTC elements fabricated through screen printing and sputtering.

\begin{tabular}{ccccc}
\hline \multirow{2}{*}{ Parameter } & \multicolumn{2}{c}{ Screen-Printed Electrode Layer } & \multicolumn{2}{c}{ Thin-Film Electrode Layer } \\
\cline { 2 - 5 } & A & B & C & D \\
\hline Initial resistance $(\mathrm{k} \Omega)$ & 3.00 & 3.25 & 3.32 & 2.98 \\
Minimum resistance value $(\mathrm{k} \Omega)$ & 0.77 & 0.79 & 0.89 & 0.76 \\
Maximum resistance value $(\mathrm{k} \Omega)$ & 4564 & 4784 & 4775 & 4450 \\
\hline$T_{c}\left({ }^{\circ} \mathrm{C}\right)$ & \multicolumn{5}{c}{175} \\
\hline
\end{tabular}

A device to estimate the allowable voltage and heat-generating temperature was fabricated (Figure 8) to examine the improvements in surface solidity, electrode layer contact, and PTC element surface uniformity resulting from the thin-film electrode production process. Power sockets in contact with both sides of the PTC element were inserted within the Al contact tube and connected to the power supplier to permit power. 


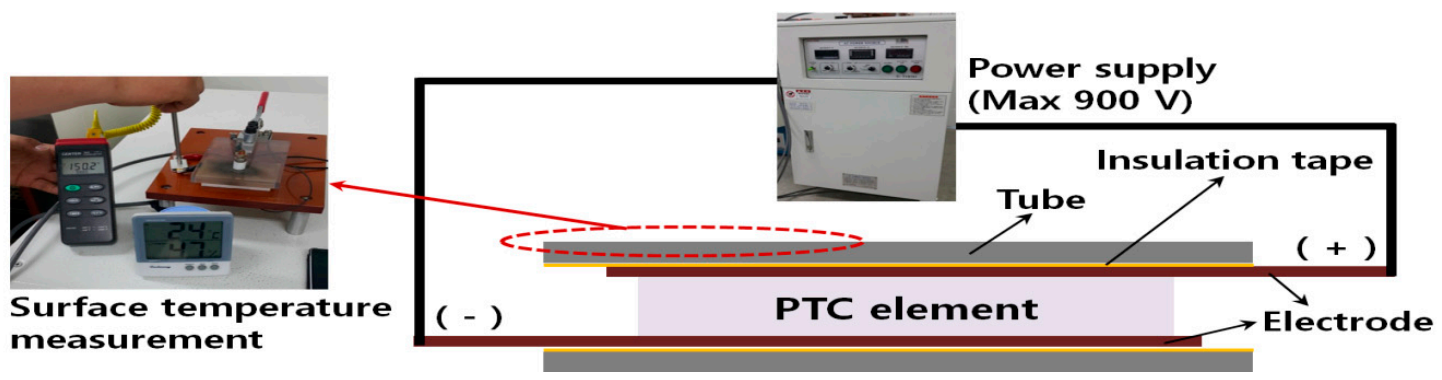

Figure 8. Schematic of the device estimating the allowable voltage and heat-generating temperature of the high-voltage PTC element prototype.

The allowable voltage was estimated at room temperature $\left(25 \pm 1^{\circ} \mathrm{C}\right)$. Voltages of 800 and $850 \mathrm{~V}$ were applied for more than $300 \mathrm{~s}$. The results are summarized in Table 4. At the reference voltage of $800 \mathrm{~V}$, the high-voltage PTC element prototypes did not exhibit any damages that could be seen with the naked eye. Furthermore, resistance variation was less than $10 \%$, confirming that the prototypes meet the performance requirements for use in EV heaters.

Table 4. Allowable voltage for the PTC element prototype for both electrode production processes.

\begin{tabular}{cccccc}
\hline \multirow{2}{*}{ Parameter } & \multicolumn{2}{c}{ Screen-Printed Electrode Layer } & \multicolumn{2}{c}{ Thin-Film Electrode Layer } \\
\cline { 2 - 6 } & & A & B & C & D \\
\hline \multicolumn{2}{c}{ Initial resistance $(\mathrm{k} \Omega)$} & 3.00 & 3.25 & 3.32 & 2.98 \\
\hline \multirow{2}{*}{$\begin{array}{c}\text { Resistance after voltage } \\
\text { withstanding test }(\mathrm{k} \Omega)\end{array}$} & Input $800 \mathrm{~V}$ & 3.29 & 3.43 & 3.47 & 3.15 \\
\cline { 2 - 6 } & Input $850 \mathrm{~V}$ & 3.34 & 3.61 & 3.52 & 3.22 \\
\hline \multicolumn{2}{c}{ Test duration $(\mathrm{s})$} & \multicolumn{3}{c}{300} \\
\hline
\end{tabular}

A contact thermometer was used to measure the element's surface heat temperature at room temperature and 330 or $350 \mathrm{~V}$. The results are summarized in Table 5. The measured surface heat temperatures were approximately $170^{\circ} \mathrm{C}$, which is the target temperature at $300 \mathrm{~V}$ for use in EV heaters.

Table 5. Surface temperature estimations for the PTC element prototypes.

\begin{tabular}{ccccccccc}
\hline \multirow{2}{*}{ Parameter } & \multicolumn{7}{c}{ Prototype } \\
\cline { 2 - 9 } & \multicolumn{2}{c}{ A } & \multicolumn{2}{c}{ B } & \multicolumn{1}{c}{ C } & D \\
\hline Input voltage $(\mathrm{V})$ & 330 & 350 & 330 & 350 & 330 & 350 & 330 & 350 \\
Surface temperature $\left({ }^{\circ} \mathrm{C}\right)$ & 172.1 & 178.3 & 173.9 & 179.4 & 171.2 & 178.6 & 172.4 & 179.2 \\
\hline
\end{tabular}

\section{Performance and Reliability of the PTC Heater}

\subsection{Heating Performance}

An electric heater was manufactured to evaluate the performance of the developed PTC element as a heating system. Figure 9 presents the schematic design and a photograph of the test device used to measure the heating capacity, efficiency, and pressure drop of the high-voltage heater. The temperature of the inlet and outlet air from the wind tunnel device was measured at 24 different locations using a $\pm 0.1{ }^{\circ} \mathrm{C}$-resolution T-type thermocouple. Temperature and pressure data were collected using a data logger (Gantner) under the following experimental conditions: input power voltage of $330 \mathrm{~V}$, inlet air temperature of $0{ }^{\circ} \mathrm{C}$, and inlet air flow rate of $300 \mathrm{~kg} / \mathrm{h}$. These factors mirror the characteristics of the air volume exiting a vehicle's Heating, Ventilation and Air Conditioning (HVAC) system blower during winter. 


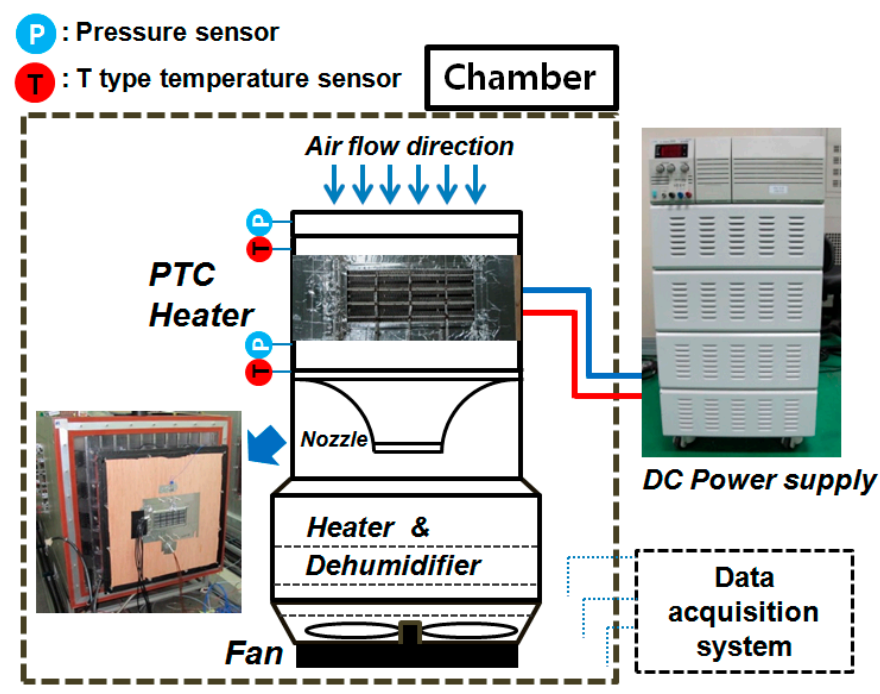

(a)

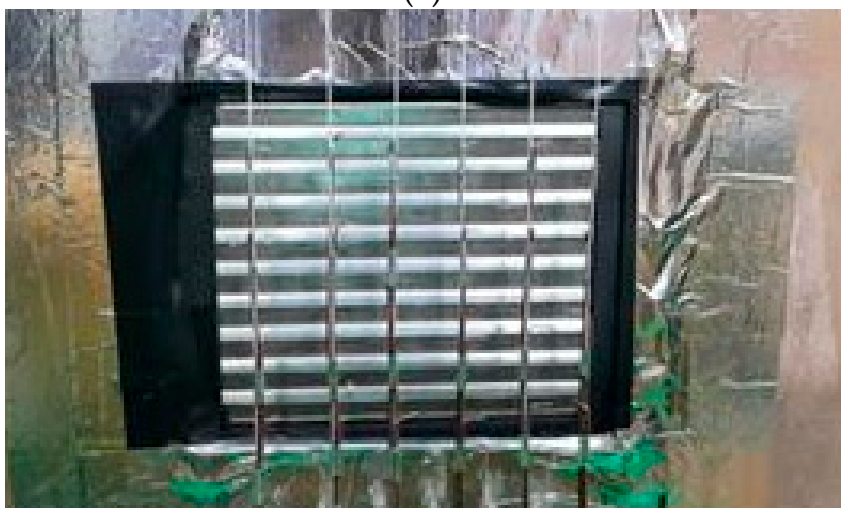

(b)

Figure 9. Schematic of the test equipment and prototype heater fabricated for evaluating heating performance. (a) Schematic diagram of the test equipment [5]; (b) Prototype heater.

Heat transfer by air, power consumption, and pressure drop were measured by evaluating the performance of the four high-voltage prototype heaters. Efficiency was defined as the ratio of the heating capacity of the heater to its power consumption (Equation (1)). The results are summarized in Table 6 . The heating capacity and efficiency were on average $4.63 \mathrm{~kW}$ and 0.952 , respectively, thereby meeting the performance requirements for use as electric heaters in EV heating systems. The pressure drop was $82.8 \mathrm{~Pa}$ on average, which is acceptable.

$$
\eta=\frac{C_{P} \times \dot{m} \times\left(T_{o}-T_{i}\right)}{V \times I}
$$

Table 6. Results of heating performance experiments.

\begin{tabular}{ccccc}
\hline \multirow{2}{*}{ Parameter } & \multicolumn{4}{c}{ Prototype Heater } \\
\cline { 2 - 5 } & A & B & C & D \\
\hline Input voltage $(\mathrm{V})$ & 331.3 & 330.8 & 331.3 & 330.9 \\
Input current $(\mathrm{A})$ & 14.7 & 14.7 & 14.6 & 14.7 \\
Power consumption $(\mathrm{kW})$ & 4.86 & 4.85 & 4.85 & 4.86 \\
Heating capacity $(\mathrm{kW})$ & 4.61 & 4.59 & 4.68 & 4.63 \\
Pressure drop $(\mathrm{Pa})$ & 83.4 & 82.4 & 82.9 & 82.6 \\
Energy efficiency & 0.944 & 0.946 & 0.964 & 0.953 \\
\hline
\end{tabular}




\subsection{Reliability}

Vibration and thermal shock test reliability tests were conducted in compliance with the relevant test conditions for PTC heaters (IEC60068-2-6 and IEC60068-2-14, respectively). Tables 7 and 8 present the heating performance results before and after the vibration and thermal shock reliability tests, respectively. After the vibration and thermal shock tests, the heating performance of the prototype heaters decreased by a maximum of $6.1 \%$ and $5.3 \%$, respectively, which is much less than that allowed $(10 \%)$. Moreover, after the reliability tests, the overall performance of the prototype heater reduced by only $5 \%$. Overall, these results prove the high reliability of the developed prototypes.

Table 7. Prototype characteristics before and after the vibration test.

\begin{tabular}{ccccc}
\hline \multirow{2}{*}{ Parameter } & \multicolumn{4}{c}{ PTC Heater } \\
\cline { 2 - 5 } & \multicolumn{2}{c}{ Before } & \multicolumn{2}{c}{ After } \\
\cline { 2 - 5 } & $\mathbf{A}$ & $\mathbf{B}$ & $\mathbf{A}^{\prime}$ & $\mathbf{B}^{\prime}$ \\
\hline Input voltage (V) & 331.3 & 330.8 & 330.3 & 329.9 \\
Input current (A) & 14.7 & 14.7 & 14.6 & 14.7 \\
Power consumption (kW) & 4.86 & 4.85 & 4.82 & 4.84 \\
Heating capacity (kW) & 4.61 & 4.59 & 4.35 & 4.31 \\
Pressure drop (Pa) & 83.4 & 82.4 & 83.7 & 83.5 \\
Energy efficiency & 0.944 & 0.946 & 0.903 & 0.890 \\
\hline
\end{tabular}

Table 8. Prototype characteristics before and after the thermal shock test.

\begin{tabular}{ccccc}
\hline \multirow{2}{*}{ Parameter } & \multicolumn{4}{c}{ PTC heater } \\
\cline { 2 - 5 } & \multicolumn{2}{c}{ Before } & $\mathbf{A}^{\prime}$ & $\mathbf{B}^{\prime}$ \\
\cline { 2 - 5 } & $\mathbf{A}$ & $\mathbf{B}$ & 330.3 & 330.4 \\
Input voltage (V) & 331.3 & 330.9 & 14.7 & 14.6 \\
Input current (A) & 14.6 & 14.7 & 4.85 & 4.84 \\
Power consumption (kW) & 4.85 & 4.86 & 4.85 & 4.45 \\
Heating capacity (kW) & 4.68 & 4.63 & 4.43 & 83.1 \\
Pressure drop (Pa) & 82.9 & 82.6 & 84.0 & 0.918 \\
Energy efficiency & 0.964 & 0.953 & 0.913 & \\
\hline
\end{tabular}

\section{Conclusions}

This study improved the sintering process to enhance surface uniformity in the manufacturing process of PTC elements for use in EV heating systems. An electrode production process using thin-film sputtering deposition was applied to ensure the heating performance of PTC elements and reduce electrode material use. In addition, a heater for an EV heating system was manufactured using the developed high-voltage PTC elements to verify their performance. The study conclusions are as follows:

(1) The proposed method realized an electrode layer of uniform thickness not exceeding $3.8 \mu \mathrm{m}$ and reduced electrode material use by approximately $69 \%$.

(2) The allowable voltage and surface heat temperature of the high-voltage PTC elements developed with the thin-film electrode were $800 \mathrm{~V}$ and $172{ }^{\circ} \mathrm{C}$, respectively, which is adequate for use in high-voltage heaters.

(3) The results of vibration and thermal shock testing were within the standard range, confirming that the developed heater was adequately reliable for use in EV vehicles.

Acknowledgments: This study was performed as a part of the Energy Technology Development project sponsored by the Ministry of Trade, Industry and Energy and was supported by the 2016 Yeungnam University Research Grant. In addition, support from E-Gun Technology is greatly appreciated. 
Author Contributions: Sung Chul Kim and Yoon Hyuk Shin organized the overall experimental evaluations and result analysis. Seung $\mathrm{Ku}$ Ahn commented on the results and conclusions. All the authors also reviewed the manuscript.

Conflicts of Interest: The authors declare no conflict of interest.

\section{Nomenclature}

$C_{\mathrm{p}}$ specific heat of air $(\mathrm{J} / \mathrm{kg} \cdot \mathrm{K})$

I current (A)

$\dot{m}$ mass flow rate of air $(\mathrm{kg} / \mathrm{s})$

$T_{c} \quad$ Curie temperature $\left({ }^{\circ} \mathrm{C}\right)$

$T_{i} \quad$ inlet air temperature $\left({ }^{\circ} \mathrm{C}\right)$

$T_{0} \quad$ outlet air temperature $\left({ }^{\circ} \mathrm{C}\right)$

$V \quad$ input voltage (V)

$\eta \quad$ energy efficiency

\section{References}

1. Yokoyama, A.; Osaka, T.; Imanishi, Y.; Sekiya, S. Thermal management system for electric vehicles. SAE Int. 2011, 4. [CrossRef]

2. Lee, J.T.; Kwon, S.J.; Lim, Y.; Chon, M.S.; Kim, D. Effect of air-conditioning on driving range of electric vehicle for various driving modes. SAE Int. 2013. [CrossRef]

3. Ahn, J.H.; Kang, H.; Lee, H.S.; Jung, H.W.; Baek, C.; Kim, Y. Heating performance characteristics of a dual source heat pump using air and waste heat in electric vehicles. Appl. Energy 2014, 119, 1-9. [CrossRef]

4. Ahn, J.H.; Kang, H.; Lee, H.S.; Kim, Y. Performance characteristics of a dual-evaporator heat pump system for effective dehumidifying and heating of a cabin in electric vehicles. Appl. Energy 2015, 146, 29-37. [CrossRef]

5. Kim, S.C.; Kim, M.S.; Hwang, I.C.; Lim, T.W. Heating performance enhancement of a $\mathrm{CO}_{2}$ heat pump system recovering stack exhaust thermal energy in fuel cell vehicles. Int. J. Refrig. 2007, 30, 1215-1226. [CrossRef]

6. Park, S.M.; Kim, S.D.; Chun Suk, J.; Lee, C.W.; Kim, J.W.; Jung, S.W. Development of intelligent-controlled high voltage PTC for eco-friendly EV. In Proceedings of the Spring Conference of KSME, Seoul, Korea, 2-3 June 2011; pp. 144-147.

7. Shin, Y.H.; Sim, S.; Kim, S.C. Performance Characteristics of a Modularized and Integrated PTC Heating System for an Electric Vehicle. Energies 2016, 9, 18. [CrossRef]

8. Kim, K.Y.; Kim, S.C.; Kim, M.S. Experimental studies on the heating performance of the PTC heater and heat pump combined system in fuel cells and electric vehicles. Int. J. Automot. Technol. 2012, 13, 971-977. [CrossRef]

9. Cen, J.; Wang, D. The metallization of PTC ceramic by magnetron sputtering. Phys. Procedia 2012, 32, $482-486$. [CrossRef]

10. Cheng, W.; Yuan, S.; Song, J. Studies on preparation and adaptive thermal control performance of novel PTC (positive temperature coefficient) materials with controllable Curie temperatures. Energy 2014, 74, 447-454. [CrossRef]

(C) 2016 by the authors; licensee MDPI, Basel, Switzerland. This article is an open access article distributed under the terms and conditions of the Creative Commons Attribution (CC-BY) license (http://creativecommons.org/licenses/by/4.0/). 